\title{
PROGRAMAS DE INCLUSÃO NA UFMG: O EFEITO DO BÔNUS E DO REUNI NOS QUATRO PRIMEIROS ANOS DE VIGEENCIA - UM ESTUDO SOBRE ACESSO E PERMANÊNCIA
}

Antônia Vitória Soares Aranha* Carolina Silva Pena**

Sérgio Henrique Rodrigues Ribeiro***

RESUMO: Este artigo apresenta uma análise do impacto da adoção do Programa de Bônus no processo de seleção da Universidade Federal de Minas Gerais (UFMG) sob a perspectiva da inclusão racial, da educação pregressa e por faixa de renda. Foram analisados dados dos últimos 13 vestibulares, contemplando os quatro primeiros anos de aplicação do bônus. Além da análise do acesso à UFMG, este artigo traz também informações a respeito da permanência de estudantes que ingressaram em cursos presenciais da UFMG nos dois primeiros anos de vigência do Programa de Bônus.

Palavras-chave: Políticas de Ação Afirmativa; Bônus; Perfil dos Estudantes.

\section{AFFIRMATIVE PROGRAMS AT UFMG: THE FIRST FOUR YEARS EFFECT OF THE AFFIRMATIVE ACTIONS NAMED ‘BONUS' AND 'REUNI ‘ - A STUDY ABOUT ENTRANCE AND PERMANENCE}

ABSTRACT: This paper presents an impact analysis of the affirmative action named "Bonus" in the selection process of the Federal University of Minas Gerais (UFMG). The analysis was made from the perspective of racial inclusion, previous education and monthly family income. The data basis was composed by information from the last thirteen years selection programs, including the four first years of "bonus" application. Besides the entrance analysis, this paper provides information about the evasion of students enrolled in UFMG presencial courses in the first two years of the "Bonus" Program.

Keywords: Affirmative Policies; “Bonus”; Students' Profiles.

\footnotetext{
*Doutora em Educação pela Pontifícia Universidade Católica de São Paulo (PUC/SP); Professora Associada da Faculdade de Educação e Pró-Reitora de Graduação da Universidade Federal de Minas Gerais (UFMG) e Pró-Reitora da UFMG. E-mail: antoniavitoria@uol.com.br

* * Mestre em Estatística pela Universidade Federal de Minas Gerais (UFMG). E-mail: carolinasend@gmail.com

*** Mestrando em Estatística pela Universidade Federal de Minas Gerais (UFMG). E-mail: sergiohrr@gmail.com
} 


\section{INTRODUC̣ÃO}

Nos últimos anos o Brasil vem passando por transformações na forma de ingresso nas universidades públicas. A ideia da entrada na universidade através de concursos vestibulares, justificada pela seleção dos mais aptos em decorrência de seu mérito escolar, passou a ser questionada. De acordo com Feres Júnior e Zoninsein (2008, p. 17), a noção contemporânea de mérito possui uma dependência profunda do valor de igualdade. Os autores definem como digno de mérito aquilo é conquistado quando os competidores são razoavelmente iguais ou, metaforicamente, partem da mesma linha de largada. Sob essa perspectiva, ao se reconhecer que existe expressiva diferenciação na qualidade da educação pregressa e no incentivo recebido por grupos de estudantes, torna-se inevitável concluir que ao se atingir o mesmo patamar quantitativo de escolaridade (a conclusão do ensino médio) não há garantia de igualdade de condições na disputa por uma vaga na educação superior (COSTA; GAMERMAN, 2011).

Diversos estudos mostraram que a probabilidade de sucesso em um concurso vestibular não é homogênea entre os candidatos, variando, entre outros fatores, de acordo com a escola de origem do candidato, o conhecimento em língua estrangeira e o nível socioeconômico (DIAS et al, 2008; FRANCO et al, 2007; BORGES; CARNIELLI, 2005). Além disso, a aplicação relativamente recente no Brasil de exames de avaliações externas em larga escala (PISA, Prova Brasil, SAEB, entre outros), com o intuito de realizar um diagnóstico do sistema educacional brasileiro, permitiu o levantamento de dados sobre a qualidade do ensino ofertado, evidenciando a diferenciação existente entre as escolas. Soares, César e Fonseca (1999) destacam ainda que o escore final de um estudante em um exame de avaliação não é influenciado somente pela escola pregressa, mas também por características pessoais do aluno e do ambiente no qual ele está inserido.

Nesse contexto, surgiram no país movimentos de reivindicação pela abertura da universidade pública aos pobres, negros, indígenas, povos do campo, quilombolas, pessoas com deficiência, dentre outros grupos sub-representados nas instituições de ensino superior (IES), sobretudo as públicas. Em decorrência desse processo diversas universidades públicas brasileiras vêm adotando medidas de inclusão social e de ações afirmativas destinadas aos estudantes oriundos desses coletivos sociais, a fim de garantir 
a igualdade de oportunidades (acesso e permanência) na educação superior (COMISSÃO DE ESTUDO E ACOMPANHAMENTO DE MEDIDAS DE INCLUSÃO SOCIAL NO CORPO DISCENTE DA UFMG, 2009).

As ações afirmativas podem ser definidas como um conjunto de políticas que visam concretizar o ideal de efetiva igualdade de acesso a bens fundamentais como a educação e o emprego (GOMES, 2005). Do ponto de vista jurídico, as políticas de ação afirmativa foram concebidas dentro de uma visão na qual se propõe a transição da noção de igualdade estática ou formal ao conceito de igualdade substantiva ou material (GOMES, 2005).

De acordo com Weisskopf (2008), um fator de particular importância para o sucesso de uma ação afirmativa é a qualidade do desempenho dos beneficiários nas instituições ou organizações para as quais receberam alguma vantagem no acesso. Especificamente no caso do acesso às universidades o autor menciona que os benefícios líquidos da política da ação afirmativa dependem do número de beneficiários que consegue concluir seu curso comparado com o número de beneficiários que não obtém sucesso.

De maneira geral, pode-se dizer que as IES têm se preocupado em realizar pesquisas sobre as suas políticas de ação afirmativa, em especial o desempenho e estratégias de permanência daqueles que ingressaram através dessas políticas. O livro apoiado pelo MEC e pela Unesco (Acesso e permanência da população negra no ensino superior) traz diversos exemplos dessa iniciativa. Assim, são apresentadas pesquisas de acesso e permanência na Universidade Federal da Bahia (UFBA), na Universidade de Brasília (UNB), na Universidade Federal de Alagoas (UFAL), na Universidade Estadual de Goiás (UEG), na Universidade do Estado do Rio de Janeiro (UERJ) e outras mais.

$\mathrm{Na}$ UFBA, analisando a permanência de alunos cotistas, a autora observa que eles usufruem de uma rede de solidariedade entre amigos, vizinhos e parentes para a compra de material didático, transporte e alimentação. Mas complementa:

A estratégia mais utilizada, entretanto, é a busca pelas notas altas a fim de garantir melhores horários nas disciplinas e poder trabalhar e estagiar, além disso esse desempenho exemplar ainda permite disputar uma bolsa de iniciação científica [...] (REIS, 2007, p. 66).

Outra pesquisa interessante foi realizada na Universidade Estadual de Mato Grosso do Sul. Segundo a autora desta, dos estudantes negros cotistas entrevistados (20 no total), pelo menos 8 afirmaram ter alguma 
dificuldade com uma ou outra matéria. "Quando perguntados sobre que estratégias formais ou informais eles estariam utilizando, afirmaram recorrer aos colegas e também aos professores.” (BENEDITO, 2007, p. 125).

Em outra publicação, um dos capítulos analisa a política de cotas da Universidade Estadual do Rio de Janeiro (UERJ), em especial a ação do Coletivo de Professores Negros e o Núcleo de Estudos Afro-Brasileiros, para garantir a permanência de alunos negros na universidade e afirma que as ações

[...] que se desenvolvem [...] com recursos do Ministério da Educação apontam para a necessidade de sua ampliação, seja no número de beneficiários, seja na quantidade de recursos financeiros destinados à sua programação [...] (GONÇALVES, 2008, p. 294).

$\mathrm{Na}$ Universidade Federal de Minas Gerais (UFMG), algumas iniciativas institucionais foram tomadas para o estabelecimento do debate sobre a inclusão sócio-racial, tais como: abertura de cursos noturnos, realização de seminários sobre a democratização do acesso na universidade pública, entre outros. Em 2008 tais iniciativas culminaram na aprovação da política de bônus pelo Conselho Universitário (Resolução n ${ }^{\circ}$ 03/2008) com aplicação a partir do vestibular de 2009. Essa medida oferece um bônus adicional de $10 \%$ na nota das provas dos candidatos que tenham cursado os sete últimos anos da educação básica em escola pública e mais 5\% para aqueles que, na mesma condição, se autodeclararem negros (pretos e pardos). $\mathrm{Na}$ ocasião, o Conselho previu uma avaliação mais detalhada, para a possível adequação da proposta, em no máximo quatro anos.

Além da implantação da política de bônus, houve a criação de $1.236^{1}$ novas vagas no vestibular de 2009 e de mais 650 vagas no ano seguinte, em decorrência da adesão da UFMG ao Programa de Apoio a Planos de Reestruturação e Expansão das Universidades Federais (Reuni). O Reuni foi instituído pelo Decreto $n^{\circ}$ 6096, de 24 de abril de 2007, como uma das ações que integram o Plano de Desenvolvimento da Educação (PDE), tendo sido criado com o objetivo de estabelecer as condições necessárias para a ampliação do acesso e permanência na educação superior brasileira no nível de graduação.

Nesse contexto, este artigo tem o propósito de fazer uma análise do impacto que essas duas alterações tiveram no processo de seleção da 
UFMG do ponto de vista da inclusão racial, da educação pregressa e por faixa de renda. Para essa finalidade será realizado um estudo temporal baseado em dados dos últimos 13 vestibulares da UFMG, contemplando os quatro primeiros anos de aplicação do bônus. Ressalta-se que, embora o bônus na UFMG tenha beneficiado exclusivamente estudantes que realizaram os sete últimos anos da educação básica em escolas públicas, para efeito de comparação com anos anteriores será considerado como egresso de escola pública aquele que tiver cursado o ensino médio, integralmente ou na maior parte nesse tipo de escola. O segundo aspecto a ser mencionado é que a UFMG só dispõe da informação referente à autodeclaração de cor ou raça dos vestibulandos a partir de 2003.

Além de analisar o efeito do Programa de Bônus na aprovação de grupos sub-representados no vestibular, este artigo traz também informações a respeito da evasão de estudantes que ingressaram em cursos presenciais da UFMG em 2009 e 2010, ou seja, nos dois primeiros anos de vigência do bônus. Dessa forma, procurou-se avaliar o efeito da política de bônus, não apenas do ponto de vista do acesso à universidade, mas também no que diz respeito à permanência.

Os dados socioeconômicos referentes ao bônus, à inscrição e aprovação no vestibular foram fornecidos pela Comissão Permanente do Vestibular (Copeve) da UFMG. Os dados socioeconômicos são informados pelo candidato mediante o preenchimento de um questionário no ato da inscrição no vestibular. Os dados relativos à evasão do corpo discente da UFMG foram fornecidos pelo Departamento de Registro e Controle Acadêmico (DRCA) dessa universidade. $\mathrm{O}$ estudo apresentado neste artigo sobre o acesso dos candidatos foi realizado exclusivamente com os dados fornecidos pela Copeve; no caso do estudo referente à permanência do corpo discente foi necessário integrar as bases de dados fornecidas pela Copeve e pelo DRCA. As análises e os gráficos apresentados neste artigo foram desenvolvidos no software $\mathrm{R}$ versão 2.10.1. (R DEVELOPMENT CORE TEAM, 2009).

\section{ANÁLISE DO ACESSO À UFMG: ATUAC̣ÃO CONJUNTA DO PROGRAMA DE BÔNUS E DO REUNI}

Essa seção mostra o histórico de procura e aprovação na UFMG de grupos raciais, de acordo com o tipo de escola em que cursaram a maior parte do ensino médio e por faixa de renda. Os gráficos mostrados à esquerda 
da Figura 1, da Figura 2 e da Figura 3 (gráfico (a)) permitem comparar a proporção de inscritos e aprovados em cada categoria de raça, origem escolar e renda analisada. Para entender a informação que pode ser extraída da análise desse tipo de gráfico, suponha que há uma urna com 100 mil bolas, sendo que 70 mil são vermelhas e 30 mil são azuis. Suponha também que se deseja selecionar mil dessas bolas e a probabilidade de escolha de qualquer uma delas é a mesma; nesse caso, é esperado que na amostra cerca de 700 bolas fossem vermelhas e 300 bolas azuis. Em termos da seleção de candidatos no vestibular, suponha, por exemplo, que 70\% dos candidatos inscritos no vestibular fossem provenientes da rede pública e 30\% da rede privada. Se não houvesse diferença na chance de aprovação dos estudantes em decorrência de sua origem escolar, seria esperado que dentro do grupo de aprovados cerca de $70 \%$ fossem alunos da rede pública e 30\% da rede privada. Quando a proporção de inscritos de determinada categoria é muito maior do que a proporção de aprovados, isso indica que essa categoria está sub-representada entre os aprovados, ou seja, a probabilidade de se observar um estudante pertencente a essa categoria entre os aprovados no concurso é menor do que a esperada.

Os gráficos mostrados à direita de cada figura (gráfico (b)) permitem avaliar o número absoluto de aprovados de cada grupo analisado.

Na Figura 1, o gráfico (a) contém o percentual de candidatos das raças branca e negra ${ }^{2}$ inscritos e aprovados nos vestibulares da UFMG de 2003 a 2012. Até o vestibular de 2009, a proporção de negros aprovados sempre esteve abaixo da proporção de inscritos, o que caracterizava a

\section{Figura 1}

\section{Análise do acesso à UFMG de acordo com a cor ou raça declarada.}
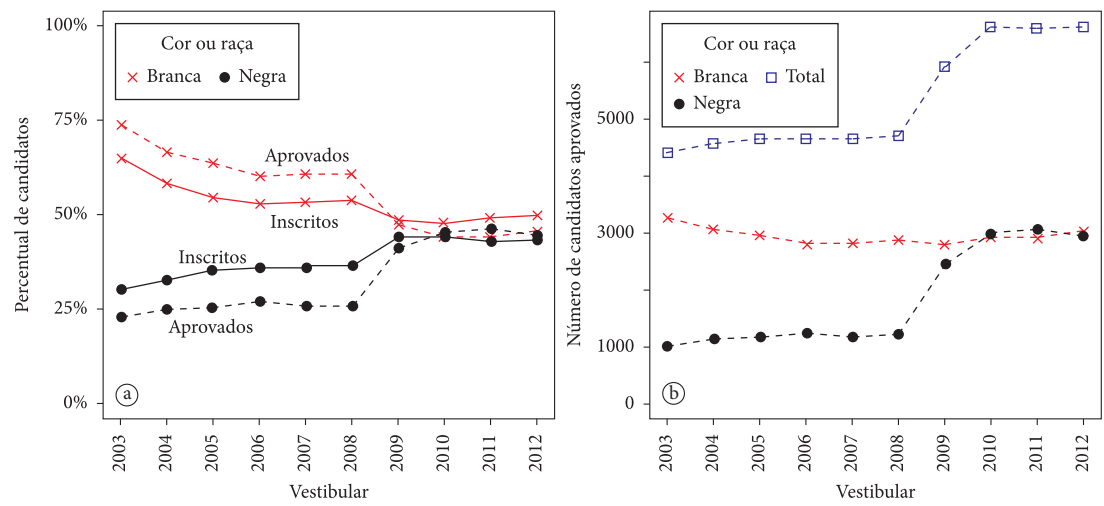
sub-representação desse grupo dentro da UFMG. O percentual de candidatos que se declararam negros e foram aprovados no vestibular no período de 2003 a 2008 variou entre 23\% e 28\%. Em 2009 esse percentual ultrapassou 40\% e nos vestibulares de 2010, 2011, 2012 ele ficou em torno de 45\%. Houve também crescimento do percentual de inscritos que se declararam negros; em 2008 esse percentual não chegava a 37\% e nos vestibulares subsequentes ele subiu para quase $45 \%$.

Deve-se destacar, no entanto, que o aumento da proporção de inscritos da raça negra a partir de 2009 pode ter ocorrido em função de um efeito de indução na declaração racial gerado pela possibilidade de obtenção de bônus no vestibular da UFMG. No entanto, faz-se necessária a realização de um estudo específico que seja capaz de avaliar se houve, de fato, alteração na declaração de cor ou raça de um grupo de candidatos em razão de um possível beneficiamento. $\mathrm{O}$ efeito de indução na declaração racial, caso venha a ser confirmado, parece ter se estabilizado, uma vez que a proporção de candidatos inscritos que se autodeclararam negros se manteve aproximadamente constante nos vestibulares subsequentes ao primeiro ano de adoção da política de bônus, não havendo indicativos de crescimento para os próximos anos.

O gráfico (b) da Figura 1 contém o número total de candidatos aprovados nos vestibulares da UFMG e o número de aprovados de acordo com a raça declarada. Nota-se que, entre os aprovados, o número de candidatos que se declararam brancos manteve-se aproximadamente constante de 2003 até 2012. Por outro lado, o número de candidatos aprovados que se declararam negros cresceu substancialmente em 2009.

\section{Figura 2}

Análise do acesso à UFMG de acordo com o tipo de escola.
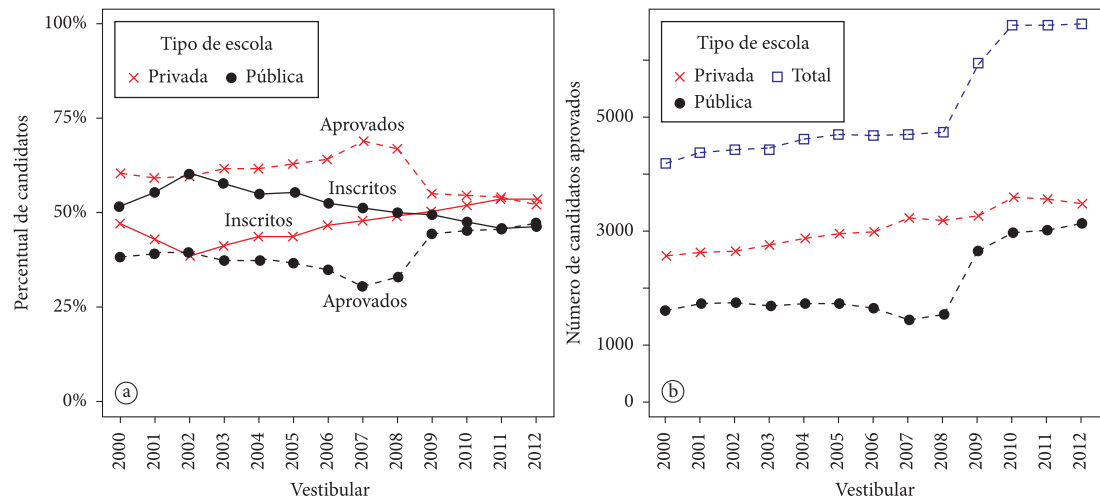
A Figura 2 mostra o comportamento histórico de procura e aprovação na UFMG de candidatos das redes pública e privada, compreendendo os vestibulares de 2000 a 2012. No gráfico (a), pode-se verificar que até a adoção do Programa de Bônus e do Reuni, a escola pública esteve fortemente sub-representada entre os aprovados da UFMG em todo o período avaliado. No vestibular de 2008, por exemplo, enquanto mais de $50 \%$ dos inscritos no concurso eram provenientes do ensino público, menos de $35 \%$ dos aprovados eram estudantes da rede pública.

As diferenças entre a proporção de inscritos e aprovados variaram de 13 a 21 pontos percentuais entre 2000 e 2008. No vestibular de 2009 essa diferença caiu para cerca de 5\% e nos vestibulares de 2011 e 2012 a proporção de inscritos e aprovados da rede pública na UFMG praticamente se equiparou. A partir do segundo ano de adoção do bônus (2010), a proporção de aprovados na UFMG provenientes da escola pública ultrapassou 45\%.

Ressalta-se, entretanto, que, apesar da adoção de medidas de ação afirmativa, a proporção de inscritos da rede pública vem caindo desde o vestibular 2002; a partir do vestibular de 2009 o número de inscritos da rede privada no vestibular da UFMG passou a superar o número de inscritos da rede pública.

No gráfico (b) da Figura 2 verifica-se que em 2009 houve um aumento acentuado do número de candidatos aprovados da rede pública. $\mathrm{O}$ aumento de vagas na UFMG em conjunto com a atuação do Programa de Bônus parecem ter propiciado maior inclusão de alunos da rede pública na UFMG. O crescimento do número de estudantes da rede privada dentro da UFMG, por outro lado, foi muito pequeno em relação à expansão do número de vagas.

\section{Figura 3}

\section{Análise do acesso à UFMG de acordo com a renda familiar mensal.}
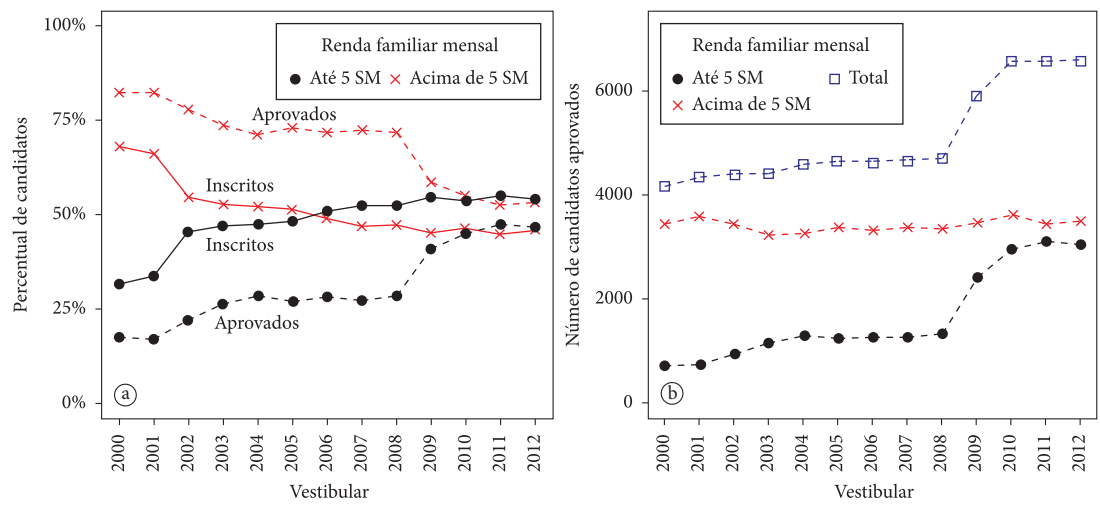
O questionário socioeconômico do vestibular da UFMG contém a seguinte questão relativa à renda do candidato: "Qual é a renda mensal do seu grupo familiar?” Essa variável contém as seguintes categorias: “menos de 1 salário mínimo", "de 1 a 2 salários mínimos", "de 2 a 5 salários mínimos", "de 5 a 10 salários mínimos”, "de 10 a 15 salários mínimos”, “de 15 a 20 salários mínimos", "de 20 a 40 salários mínimos”, “de 40 a 60 salários mínimos", "acima de 60 salários mínimos".

Neste artigo os candidatos foram divididos em dois grupos de renda familiar mensal: candidatos com renda familiar de até cinco salários mínimos, através da união das três primeiras categorias de renda do questionário da UFMG, e candidatos com renda superior a cinco salários mínimos, incluindo os candidatos das demais categorias. A definição desses dois grupos de renda se deu por duas razões principais. A primeira delas é a pequena representatividade de candidatos com renda familiar mensal nas duas primeiras faixas de renda ("menos de 1 salário mínimo" e "de 1 a 2 salários mínimos”) em alguns dos vestibulares sob análise; entre os vestibulares de 2000 e 2012 a soma do percentual de candidatos presentes nessas duas faixas renda variou entre $7 \%$ e $20 \%$.

A segunda motivação é o fato de cerca de $70 \%$ dos candidatos ao vestibular da UFMG, em todo o período analisado, ter declarado que quatro pessoas ou mais vivem da renda mensal do seu grupo familiar. Dessa forma, para a maior parte dos candidatos ao vestibular da UFMG, uma renda familiar mensal inferior a cinco salários mínimos implica em possuir renda mensal per capita inferior a um salário mínimo e meio. Essa faixa de renda (até um salário mínimo e meio per capita) é adotada pelo governo federal como um dos critérios para a concessão de bolsas integrais dentro do Programa Universidade para Todos (ProUni) e para o Programa Nacional de Assistência Estudantil (Decreto n 7.234 de 19 julho de 2010).

A partir do gráfico (a) da Figura 3 verifica-se que em todo o período avaliado houve um crescimento da proporção de inscritos com renda familiar de até cinco salários mínimos. No vestibular de 2000 a proporção de inscritos com esse perfil era menor do que 35\%, no vestibular de 2002 essa proporção aumentou para mais de 45\% e nos vestibulares de 2011 e de 2012 ficou em torno de $55 \%$. A proporção de aprovados nessa faixa de renda também cresceu em todo o período, embora somente a partir da adoção do bônus e do Reuni tenha sido observado um salto nesse crescimento. No vestibular 
de 2000, menos de 20\% dos aprovados apresentavam renda familiar mensal inferior a cinco salários mínimos; no vestibular de 2008 foram quase 30\% e nos vestibulares de 2011 e de 2012 mais de 45\%.

No gráfico (b) da Figura 3 pode-se observar que a partir do vestibular de 2009 houve um grande aumento do número de candidatos aprovados na UFMG com renda familiar mensal de até cinco salários mínimos. Nota-se que apesar da expansão de vagas sofrida pela UFMG, o número de candidatos aprovados com renda familiar mensal superior a cinco salários mínimos manteve-se aproximadamente constante, não acompanhando o crescimento da universidade.

\section{ANÁLISE DO ACESSO À UFMG: EFEITO DO PROGRAMA DE BÔNUS}

A seção anterior mostrou o histórico de procura e aprovação na UFMG considerando as informações dos últimos 13 vestibulares. Pôde-se avaliar a transformação ocorrida no perfil do aluno ingressante na UFMG em decorrência da ação conjunta do Reuni e do Programa de Bônus. O objetivo dessa seção é fazer uma análise da inclusão que teria sido gerada pela adoção do Programa de Bônus sem a presença do Reuni. O que se deseja avaliar é se o ingresso na UFMG de candidatos oriundos de grupos sub-representados ocorreu de forma efetiva nas vagas que existiam tradicionalmente na UFMG ou se a inclusão mostrada nesse artigo é fruto fundamentalmente das novas vagas e dos novos cursos abertos pelo Reuni.

Para realizar essa análise os gráficos mostrados na seção anterior foram reconstruídos considerando somente os cursos e vagas existentes na UFMG até o vestibular de 2008. Por exemplo, o curso de Letras Noturno possuía, no vestibular de 2008, 160 vagas; a partir do vestibular de 2009 houve um aumento para 260 vagas. $\mathrm{Na}$ análise apresentada nessa seção foram considerados aprovados, no curso de Letras Noturno, somente os 160 candidatos com melhor desempenho nesse curso nos vestibulares de 2009, 2010, 2011 e 2012. Além disso, cursos como Arquivologia e Gestão Pública, criados a partir de 2009 , foram retirados da análise apresentada nessa seção. 
No Anexo I é mostrada uma tabela que contém o número total de vagas por curso no vestibular de 2008, o número de aprovados nos vestibulares de 2009 a 2012 e o número de vagas mantidas na análise apresentada nessa seção.

Considerando somente as vagas tradicionalmente ofertadas pela UFMG antes da adesão ao REUNI, pode-se verificar a partir da Figura 4 que, no Vestibular de 2008, cerca de 25\% dos aprovados se declararam negros, após a adoção do Programa de Bônus esse percentual ultrapassou 40\%.

Figura 4

Efeito do Programa de Bônus no acesso à UFMG de acordo com a cor ou raça declarada.
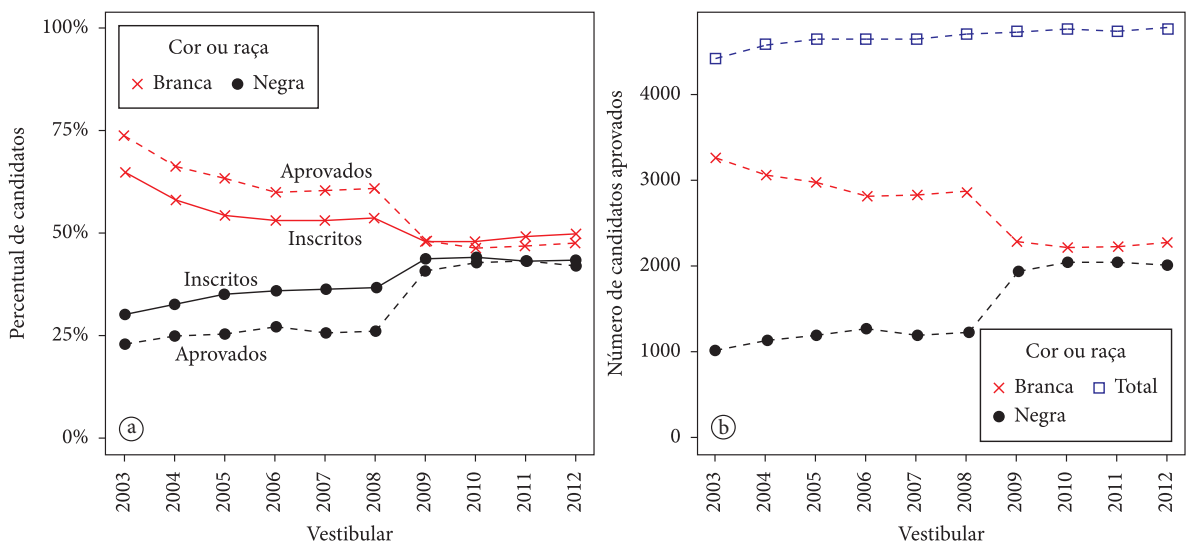

Figura 5

Efeito do Programa de Bônus no acesso à UFMG de acordo o tipo de escola.
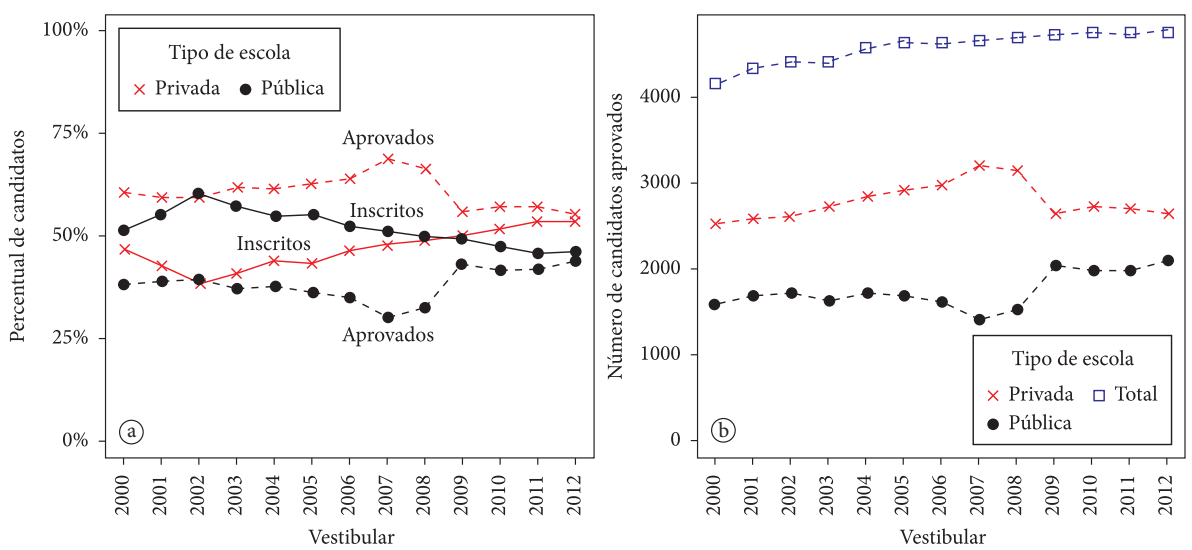
Figura 6

Efeito do Programa de Bônus no acesso à UFMG de acordo com a renda familiar mensal.
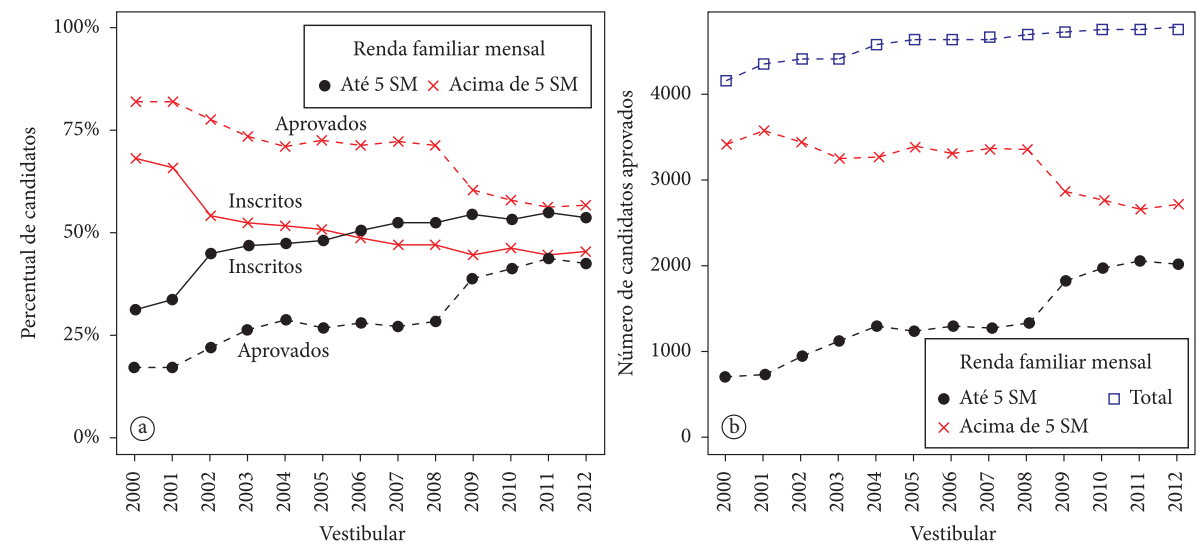

No que concerne à educação pregressa, verifica-se a partir da Figura 5 que os alunos da rede pública representavam menos de 35\% dos aprovados na UFMG em 2008, no vestibular de 2012 foram quase 45\%. Com respeito à renda familiar mensal, verifica-se a partir da Figura 6 que no Vestibular de 2008 os candidatos aprovados com renda de até cinco salários mínimos representavam menos de 30\% dos aprovados, nos vestibulares de 2010, 2011 e 2012 esse percentual ultrapassou 40\%.

\section{ANÁLISE DA PERMANÊNCIA NA UFMG}

A partir da segunda metade do século XX a evasão de estudantes nos cursos de graduação passou a despertar maior preocupação das universidades públicas brasileiras e também do Ministério da Educação. Nesse período foi divulgada uma série de estudos (BRAGA; MIRANDA-PINTO; CARDEAL, 1997; PAREDES, 1994; PRADO, 1990; RAMOS, 1995), havendo ainda a instituição de uma Comissão Especial de Estudos sobre Evasão (BRASIL, 1996). O trabalho realizado por essa comissão foi considerado pioneiro por sua abrangência nacional e também pela sistematização dos processos de coleta e tratamento dos dados (BRASIL, 1996). 
A preocupação com a redução da evasão na educação superior se tornou uma importante pauta na política educacional do país, estabelecendo-se como uma das diretrizes do Reuni. Uma das metas globais definidas para esse programa é a elevação gradual da taxa de conclusão média dos cursos de graduação presenciais para 90\%, utilizando como estratégias principais a redução das taxas de evasão e a ocupação de vagas ociosas.

A UFMG possui uma política de ocupação de vagas remanescentes que tem apresentado bons resultados. As vagas geradas por evasão são ofertadas novamente através de quatro procedimentos: rematrícula, reopção, transferência e obtenção de novo título. As duas primeiras são destinadas a estudantes da própria universidade consistindo, respectivamente, na readmissão de alunos excluídos e na mudança de curso.

Apesar disso, entende-se que é importante criar políticas de permanência na universidade em detrimento à reocupação das vagas. Nesse contexto torna-se necessária a realização de um acompanhamento das mudanças que têm ocorrido na universidade, em razão da adoção de políticas de ação afirmativa, no sentido de criar estratégias que possam minimizar a evasão.

Esse artigo avaliou, ao final do $1^{\circ}$ semestre de 2011, a situação de alunos que ingressaram na UFMG via vestibular em cursos presencias entre o $1^{\circ}$ semestre de 2009 e o $2^{\circ}$ semestre de 2010 . A seleção desse conjunto específico se deu em razão da possibilidade de comparar o comportamento de alunos beneficiados pelo Programa de Bônus (bonista) e os não beneficiados (não bonistas). Por outro lado, o prazo ${ }^{3}$ de integralização curricular das turmas que ingressaram a partir do $1^{\circ}$ semestre de 2009 não estava completo no período estudado; dessa forma os dados disponíveis até a presente data não permitem contemplar toda a trajetória das turmas até a conclusão ou evasão do curso. Ainda assim, é possível avaliar o comportamento de permanência e evasão na fase inicial de contato do aluno com a vida acadêmica dentro da UFMG.

A situação de um discente na UFMG é caracterizada pelo Departamento de Registro e Controle Acadêmico (DRCA) de três formas básicas: normal, trancamento ou exclusão. A exclusão do aluno do corpo discente da UFMG pode caracterizar evasão ou não; nesse último caso, ocorre devido à conclusão do curso, ao falecimento ou a alguma 
infração legal. Neste artigo o foco principal de estudo é a exclusão por evasão, podendo ocorrer pelos seguintes motivos: transferência para outra instituição, desistência formal do curso, infrequência em todas as disciplinas no semestre anterior, não matrícula no semestre, atingir três rendimentos semestrais globais insuficientes ou exceder o prazo de integralização curricular.

Em um total de 12.424 discentes avaliados que ingressaram em cursos presenciais da UFMG entre o $1^{\circ}$ semestre de 2009 e o $2^{\circ}$ semestre de 2010, 11.545 (92,92\%) encontravam-se em situação normal no curso ao final do $1^{\circ}$ semestre de 2011, 43 (0,35\%) haviam trancado o curso, 827 (6,66\%) foram excluídos do corpo discente por evasão e $9(0,07 \%)$ foram excluídos por razões que não caracterizam evasão (conclusão do curso, por exemplo). Entre os 827 candidatos que evadiram da UFMG, 457 (55,26\%) deles foi por não matrícula no semestre, $237(28,66 \%)$ por desistência formal do curso e 102 (12,33\%) por infrequência em todas as disciplinas no semestre anterior. Esses três motivos conjuntamente foram responsáveis por $96,25 \%$ da evasão sob análise nesse artigo.

Um dado importante que deve ser considerado na elaboração de políticas de permanência na universidade é que a evasão não ocorre de forma homogênea entre as Grandes Áreas do conhecimento. No conjunto de discentes analisados, até o final do $1^{\circ}$ semestre de 2011, o maior percentual da evasão ocorreu entre aqueles que ingressaram em cursos da área de Ciências Exatas e da Terra (11,53\%). Os menores percentuais de evasão, por outro lado, foram observados nas áreas de Engenharias, Saúde e Biológicas, correspondendo, respectivamente, a 4,20\%, 4,55\% e 4,76\%. Dessa forma, ao comparar a situação de evasão e permanência de diferentes grupos é importante avaliar a distribuição destes entre as Grandes Áreas do conhecimento e entre os cursos. Os resultados apresentados neste artigo serão calculados para as oito Grandes Áreas do conhecimento (Agrárias; Biológicas; Engenharias; Exatas e da Terra; Humanas; Linguística, Letras e Arte; Saúde; e Sociais Aplicadas) e não por curso; a principal razão para isso é que a análise realizada ao nível dos cursos está mais sujeita a flutuações decorrentes de pequenos tamanhos de amostra. A Tabela 1 mostra para cada grande área do conhecimento presente na UFMG a situação de alunos bonistas e não bonistas. 
A partir da Tabela 1 verifica-se que o percentual de evasão dos alunos que receberam bônus no vestibular (bonistas) foi menor que o percentual de evasão dos alunos não bonistas para todas as Grandes Áreas, com exceção da área de Agrárias. A maior diferença ocorreu nas áreas de Ciências Humanas e de Linguística, Letras e Artes.

Avaliando-se a evasão dos estudantes de acordo com o semestre de ingresso na UFMG, observa-se que entre aqueles que ingressaram no $1^{\circ}$ semestre de 2009, a evasão de bonista, até o final do $1^{\circ}$ semestre de 2011, foi maior nas áreas de Agrárias (15,29\% contra 9,82\%), Biológicas (6,00\% contra 4,00\%) e Ciências Exatas e da Terra (20,63\% contra 18,02\%). Entre os alunos que ingressaram no $2^{\circ}$ semestre de 2009 , a evasão de bonista foi menor em todas as áreas. No caso dos ingressantes no $1^{\circ}$ semestre de 2010, a evasão de bonistas foi maior somente na área de Agrárias (12,35\% contra 5,88\%). Entre aqueles que ingressaram no $2^{\circ}$ semestre de 2010 a evasão de bonistas foi maior somente na área de Biológicas $(2,78 \%$ contra $0,00 \%)$.

A Tabela 2 mostra o comportamento de evasão dos discentes de acordo com o tipo de escola em que cursaram a maior parte do ensino médio. Verifica-se que o que o percentual de alunos que evadiram da UFMG provenientes da rede privada $(7,10 \%)$ foi muito próximo do percentual de evasão observado entre os alunos das escolas públicas federais (7,07\%). O mesmo comportamento foi observado entre as escolas públicas estaduais (5,84\%) e as escolas públicas municipais (5,78\%). Na área de Agrárias o maior percentual de evasão foi observado entre os discentes da rede pública estadual (11,01\%); as áreas de Biológicas, Engenharias e Saúde de modo geral apresentaram baixo número e proporção de evadidos. $\mathrm{Na}$ área de Ciências Exatas, por outro lado, a evasão pode ser considerada alta em relação a outras áreas para todos os tipos de escola. $\mathrm{Na}$ área de Ciências Humanas a evasão é especialmente alta entre alunos da rede privada e da rede pública federal. Na área de Linguística, Letras e Artes a maior evasão ocorreu entre alunos da rede privada e na área de Sociais Aplicadas entre alunos da escola pública federal. 


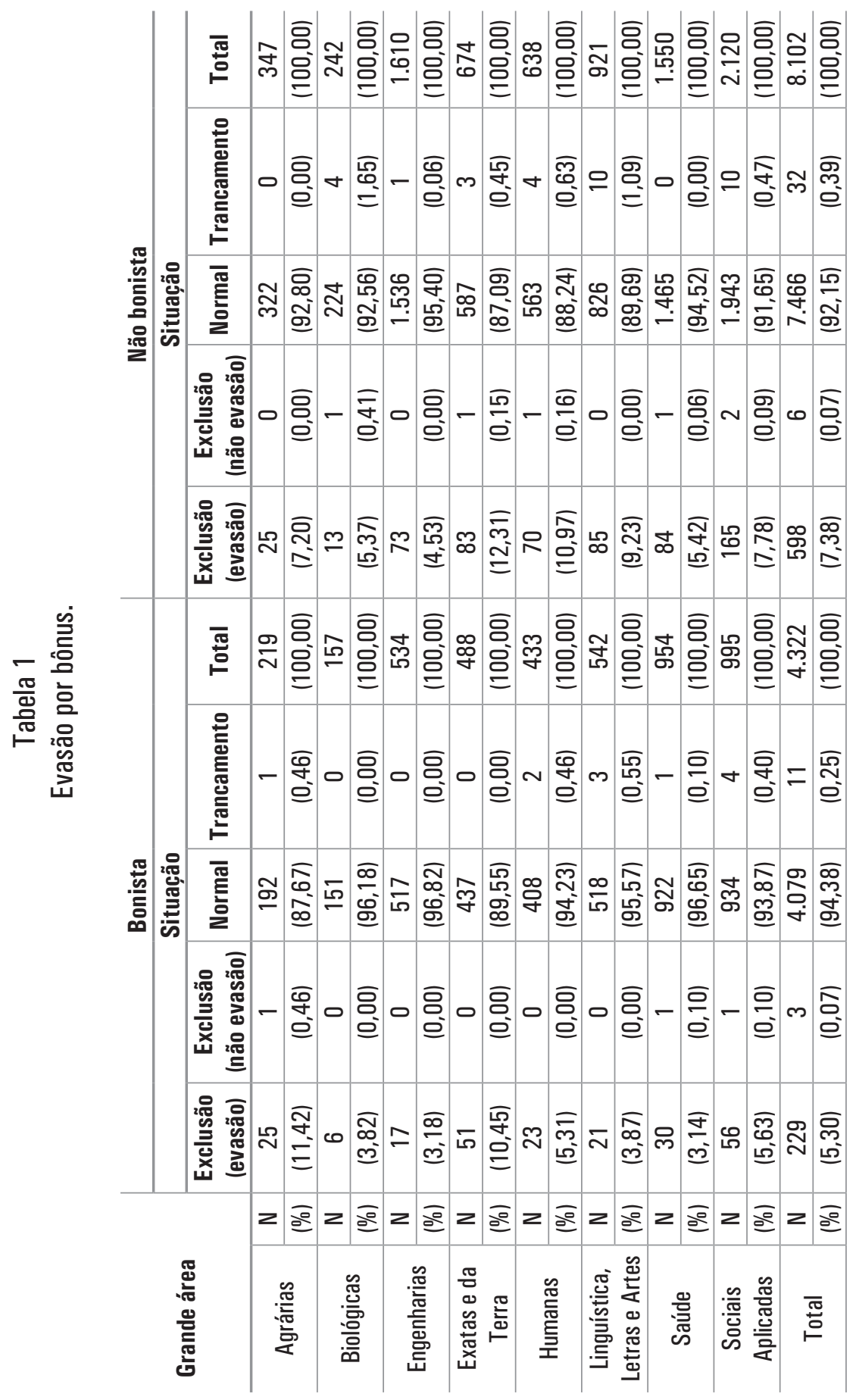




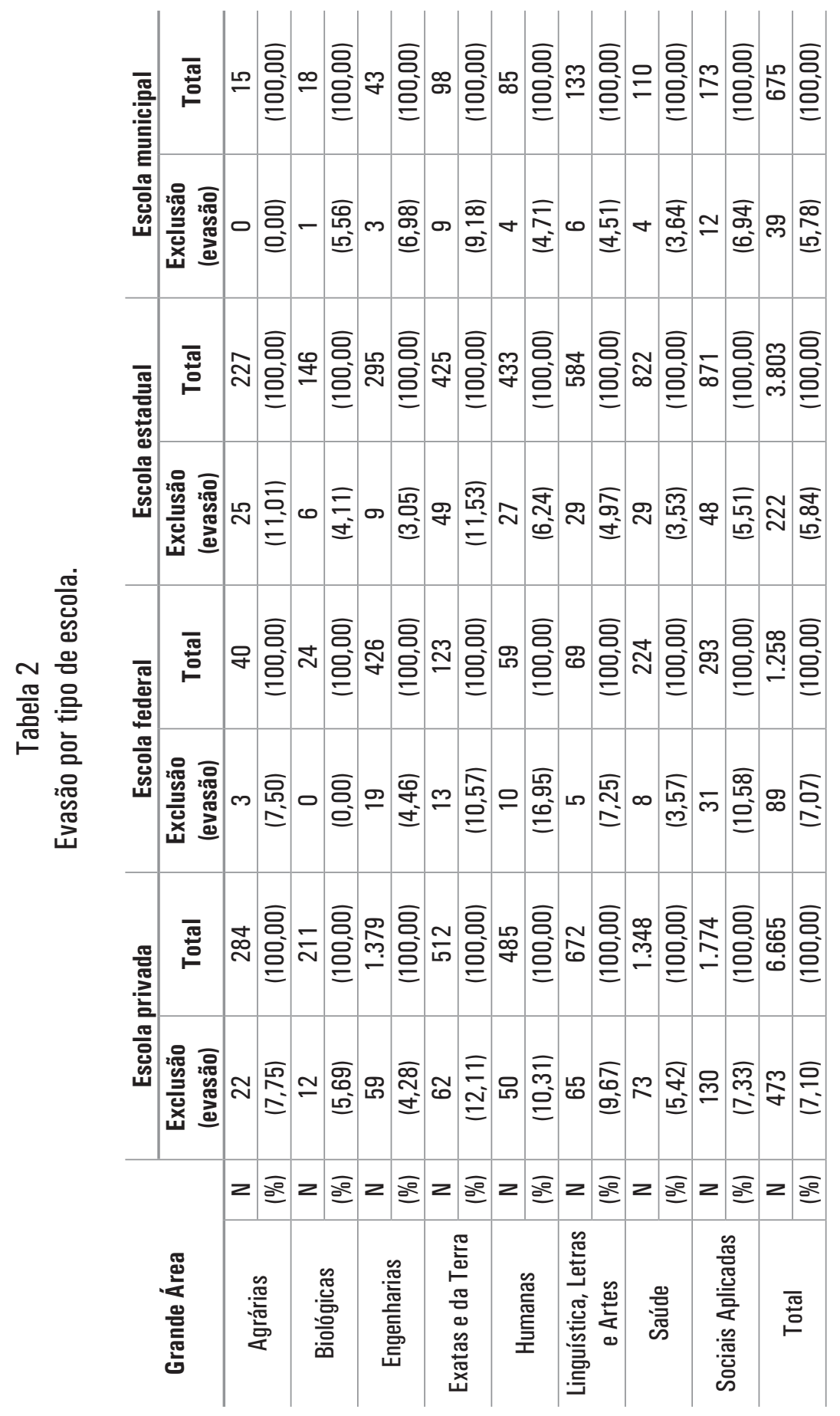




\section{CONCLUSÃO}

Este artigo apresentou dados de acesso à UFMG no que concerne à declaração de cor ou raça, tipo de escola e renda familiar mensal, desde o vestibular de 2000 até o vestibular de 2012. No vestibular de 2009 houve duas importantes alterações que parecem ter sido responsáveis pela alteração do perfil de discente ingressante na UFMG. A primeira delas foi a implantação da política de bônus que concedia um adicional de $10 \%$ na pontuação obtida no vestibular a candidatos que frequentaram escola pública da $5^{\mathrm{a}}$ série do ensino fundamental ao último ano do ensino médio e de $15 \%$ para aqueles que, na mesma condição, se autodeclarassem negros (pretos e pardos). A segunda alteração foi a adesão ao Programa de Apoio a Planos de Reestruturação e Expansão das Universidades Federais (Reuni), o que possibilitou a criação de quase 2.000 novas vagas.

Os dados analisados neste artigo mostraram que, nos vestibulares anteriores à adoção do Reuni e do Programa de Bônus na UFMG, os candidatos que se autodeclaravam negros sempre estiveram sub-representados na lista de aprovados, em comparação com a relação de candidatos inscritos. Isso significa que até a adoção desses dois programas de inclusão, a proporção de estudantes da raça negra era menor do que a esperada dentro do conjunto de candidatos aprovados. Se não houvesse qualquer diferença na chance de aprovação de candidatos brancos e negros, seria esperado que o grupo de candidatos aprovados refletisse o grupo de candidatos inscritos em termos de proporções. A partir da adoção desses dois programas, houve um aumento tanto na proporção de candidatos inscritos quanto de aprovados que se autodeclararam negros; a proporção de inscritos e aprovados da raça negra praticamente se equiparou.

Os dados analisados sobre a educação pregressa dos candidatos da UFMG mostraram que a proporção de alunos aprovados da rede pública era expressivamente inferior à proporção de inscritos até o vestibular de 2008. A partir do vestibular de 2009 a proporção de candidatos aprovados da rede pública cresceu substancialmente, praticamente se igualando à proporção de inscritos nos vestibulares de 2011 e 2012. Apesar disso, desde o vestibular de 2002 o percentual de inscritos da rede pública passou a apresentar tendência decrescente. Embora os programas de ação afirmativa adotados pela universidade tenham resultado em um grande aumento do percentual de alunos da rede pública entre os aprovados, a UFMG passou a ser procurada majoritariamente por candidatos da rede privada desde o vestibular de 2009. 
Este artigo mostrou também que após a adoção do Reuni e do Programa de Bônus houve uma redução na distância entre a proporção de candidatos inscritos e aprovados com renda familiar mensal de até cinco salários mínimos, embora essa diferença ainda não tenha sido eliminada. A partir do vestibular de 2009 houve um salto expressivo na aprovação de candidatos provenientes de famílias com essa faixa de renda; observou-se também que há uma tendência de crescimento da proporção desse grupo de candidatos entre os inscritos no vestibular da UFMG.

Este artigo trouxe ainda dados sobre o efeito de inclusão ocorrido nas vagas presentes na UFMG até o vestibular de 2008, ou seja, antes da adesão ao Reuni. Essa análise permitiu avaliar o efeito do Programa de Bônus no preenchimento das vagas tradicionais da UFMG. Verificou-se que a partir do vestibular de 2009 ocorreu um aumento do número de candidatos aprovados que se declararam negros, de candidatos oriundos da rede pública e de candidatos com renda familiar mensal de até cinco salários mínimos nas vagas existentes na UFMG antes da adoção do Reuni. Isso indica que o Programa de Bônus exerceu um efeito de inclusão nas vagas tradicionais da universidade.

É importante destacar, no entanto, que esse trabalho traz um olhar geral do quadro da UFMG. Apesar do crescimento observado nos últimos anos, quando a análise é realizada dentro de alguns cursos específicos, grupos de candidatos que se autodeclararam negros, estudantes da rede pública e estudantes com renda familiar mensal de até cinco salários mínimos ainda se mantêm sub-representados entre os aprovados. De modo geral o Programa de Bônus parece ter gerado um efeito de inclusão em grande parte dos cursos da UFMG, mas esse efeito é bastante variado.

Além da análise do acesso à UFMG, neste artigo foram apresentados dados sobre a permanência dos discentes na instituição, considerando o grupo de alunos que ingressaram entre o $1^{\circ}$ semestre de 2009 e o $2^{\circ}$ semestre de 2010 em cursos presenciais da UFMG. Verificou-se que no universo de discentes analisados a maior evasão ocorreu na área de Ciências Exatas e da Terra e os menores percentuais nas áreas de Engenharias, Saúde e Biológicas.

Nos anos iniciais de ingresso dos estudantes na vida acadêmica da UFMG, o percentual de evasão dos alunos que receberam bônus no vestibular foi menor que o percentual de evasão dos alunos que não receberam o benefício para todas as Grandes Áreas, com exceção da área de Agrárias. Ressalta-se, entretanto, que é importante fazer uma nova avaliação decorrido o prazo de integralização curricular dos ingressantes na universidade no período de vigência do bônus. 


\section{REFERÊNCIAS}

BENEDITO, V. L. Universidade Plural, País de Cidadãos: ações afirmativas desafiando paradigmas na Universidade Estadual de Mato Grosso do Sul. In: LOPES, M. A.; BRAGA, M. L. S. Acesso e Permanência da População Negra no Ensino Superior. Brasília: Ministério da Educação, Organização das Nações Unidas para a Educação a Ciência e a Cultura, 2007. BORGES, J. L. G.; CARNIELLI, B. L. Educação e estratificação social no acesso à universidade pública. Cadernos de Pesquisa, São Paulo, v. 35, n. 124, 2005.

BRAGA, M. M.; MIRANDA-PINTO, C. O. B.; CARDEAL, Z. L. Perfil sócio-econômico dos alunos, repetência e evasão no curso de Química da UFMG. Química Nova, São Paulo, v. 20, p. 438-44, 1997. http://dx.doi.org/10.1590/S0100-40421997000400017

BRASIL. Ministério da Educação. Secretaria de Educação Superior - SESU. Associação Nacional dos Dirigentes das Instituições Federais de Ensino Superior - ANDIFES. Associação Brasileira dos Reitores das Universidades Estaduais e Municipais - ABRUEM. Diplomação, retenção e evasão nos cursos de graduação em instituições de ensino superior públicas. Revista Avaliação, Campinas, n. 2, p. 55-65, 1996.

COMISSÃO DE ESTUDO E ACOMPANHAMENTO DE MEDIDAS DE INCLUSÃO SOCIAL NO CORPO DISCENTE DA UFMG - CAIS. Disponível em: < http://www. ufmg.br/cais>. Acesso em: dez. 2011.

COMISSÃO DE ESTUDO E ACOMPANHAMENTO DE MEDIDAS DE INCLUSÃO SOCIAL NO CORPO DISCENTE DA UFMG - CAIS. Relatório de Atividades. Belo Horizonte, 2009.

COSTA, M.; GAMERMAN, D. Escolhendo os efetivamente melhores: um modelo alternativo de seleção ao ensino superior. Rio de Janeiro: Instituto de Matemática, Universidade Federal do Rio de Janeiro, 2011. Relatórios Técnicos, n. 240. Disponível em: <http:/ /www.dme. im.ufrj.br/arquivos/publicacoes/arquivo240.pdf>. Acesso em: 25 mar. 2012.

DIAS, T. F. S. et al. Cursos diurnos e noturnos: fatores de aprovação no vestibular da UFMG. Cadernos de Pesquisa, São Paulo, v. 38, p. 127-146, 2008. http://dx.doi.org/10.1590/ S0100-15742008000100006

FERES JÚNIOR, J. F.; ZONINSEIN, J. A consolidação da ação afirmativa no ensino superior brasileiro. In: FERES JÚNIOR, J. F.; ZONINSEIN, J. (Orgs.). Ação afirmativa no ensino superior brasileiro. Belo Horizonte: UFMG; Rio de Janeiro: Iuperj, 2008., p. 9-33.

FRANCO, G. C. et al. Identificando as características associadas com a aprovação de candidatos de Escolas Públicas e Privadas, Vestibular-2004, UFMG. Educação em Revista, Belo Horizonte, v. 46, p. 167-194, 2007.

GOMES, J. B. B. A recepção do instituto da ação afirmativa pelo Direito Constitucional brasileiro. In: SANTOS, S. A. (Org.). Ações afirmativas e combate ao racismo nas Américas. Brasília: MEC; Seca, 2005. p. 45-80.

GONÇALVES, M. A. R. Sistema de Reserva de Vagas na Universidade do Rio de Janeiro e as Ações do Núcleo de Estudos Afro-Brasileiro da UERJ. In: SISS, A. (Org.). Diversidade étnico-racial e educação superior brasileira: experiências de intervenção. Rio de Janeiro: Quartel, 2008. PAREDES, A. S. A Evasão do Terceiro Grau em Curitiba. São Paulo: NUPES-USP, 1994.

PRADO, F. D. Acesso e evasão de estudantes na graduação: A situação do curso de Física da USP. São Paulo: Universidade de São Paulo, 1990. Tese de doutorado não-publicada. 
R DEVELOPMENT CORE TEAM. R: A language and environment for statistical computing. Vienna: R Foundation for Statistical Computing, 2009. Austria. Disponível em: <http://www.R-project.org>.

RAMOS, M. N. Quadro de evasão na UFPE: metodologia, causas e ações. Recife: Pró-Reitoria para assuntos acadêmicos, 1995.

REIS, D. B. Acesso e Permanência de Negros(as) no Ensino Superior: o caso da UFBA. In: LOPES, M. A.; BRAGA, M. L. S. Acesso e Permanência da População Negra no Ensino Superior. Brasília: Ministério da Educação, Organização das Nações Unidas para a Educação a Ciência e a Cultura, 2007.

SOARES, J. F.; CÉSAR, C. C.; FONSECA, J. A. Desempenho das escolas de ensino médio de Belo Horizonte no vestibular da UFMG. Revista Brasileira de Estatística, Rio de Janeiro, v. 60. n. 213, p. 95-116, 1999.

WEISSKOPF, T. E. A experiência da Índia com a ação afirmativa na seleção para o ensino superior. In: FERES JÚNIOR, J. F.; ZONINSEIN, J. (Orgs.). Ação afirmativa no ensino superior brasileiro. Belo Horizonte: UFMG; Rio de Janeiro: IUPERJ, 2008. p. 35-60.

\section{NOTAS}

${ }^{1}$ Fonte: Manual do candidato/Vestibular UFMG 2008, Edital do Vestibular 2009 e Edital do Vestibular 2010.

${ }^{2}$ Considera-se negro quem se declarou pardo ou preto.

${ }^{3}$ Por prazo de integralização curricular entende-se o tempo máximo que o estudante pode permanecer no curso.

Recebido: 22/08/2012

Aprovado: 22/11/2012

Contato:

Universidade Federal de Minas Gerais Faculdade de Educação Departamento de Administração Escolar Av. Antonio Carlos, 6627, Pampulha CEP $31270-901$ Belo Horizonte, MG 


\section{ANEXO I}

No Anexo I são apresentadas as vagas mantidas na análise realizada na seção 3 deste artigo. Os cursos e vagas criadas após o vestibular de 2008 foram filtrados para a obtenção dos dados apresentados nessa seção. No entanto é preciso fazer nota de algumas situações específicas. No vestibular de 2010 o curso de Comunicação Social (100 vagas em 2008) foi subdividido em três novos cursos: Comunicação Social (Jornalismo/Relações Públicas) Diurno com 40 vagas, Comunicação Social (Jornalismo/Relações Públicas) Noturno com 40 vagas e Comunicação Social (Jornalismo/Publicidade) com 40 vagas. $\mathrm{Na}$ análise esses três novos cursos foram mantidos com o seu total de vagas.

No vestibular de 2011 o curso de Educação Física (110 vagas em 2008) deu origem a dois novos cursos: Educação Física Bacharelado e Educação Física Licenciatura, cada um com 60 vagas. No vestibular de 2012 o curso de Educação Física passou a ser dividido em três cursos: Educação Física Bacharelado Diurno (60 vagas), Educação Física Bacharelado Noturno (30 vagas) e Educação Física Licenciatura (60 vagas). Em ambos os vestibulares, todos os novos cursos derivados do curso de Educação Física foram mantidos. O curso de Música Bacharelado recebeu um tratamento particular devido à existência de inúmeras habilitações, o que dificulta a retirada de vagas do curso; por essa razão também nesse curso todas as vagas criadas após o vestibular de 2008 foram mantidas na análise.

Além das situações mencionadas, podem ocorrer variações no número total de aprovados devido ao não preenchimento do total de vagas disponíveis em alguns cursos, como foi o caso do curso de Música Bacharelado no vestibular de 2011. Na Tabela 3 pode-se verificar o número de vagas existente na UFMG no vestibular de 2008, ou seja, antes da adoção Reuni. Para os vestibulares subsequentes (2009 a 2012), a Tabela 3 mostra o número total de aprovados em cada curso e o número de vagas consideradas na análise mostrada na seção 3 . 


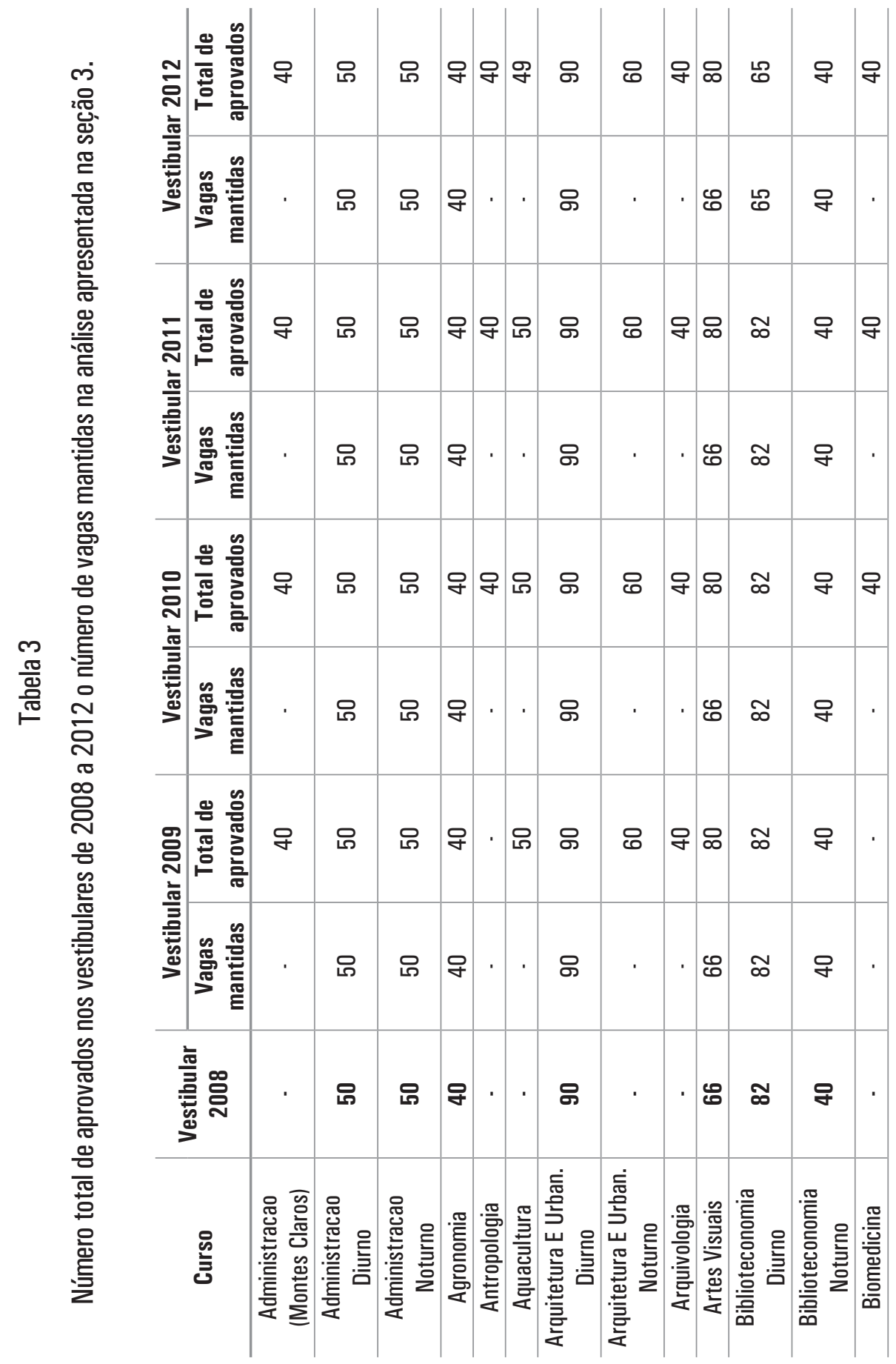




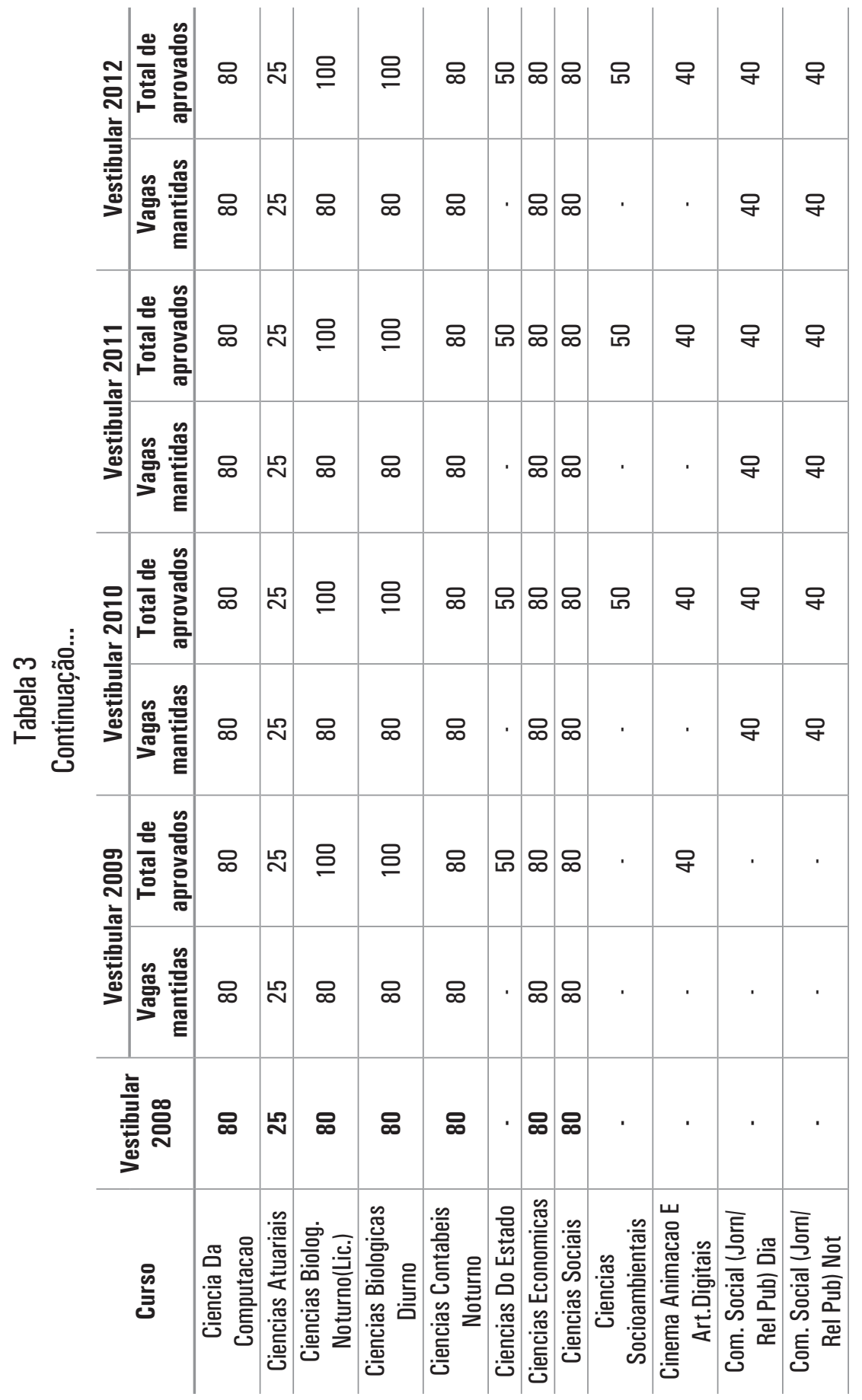




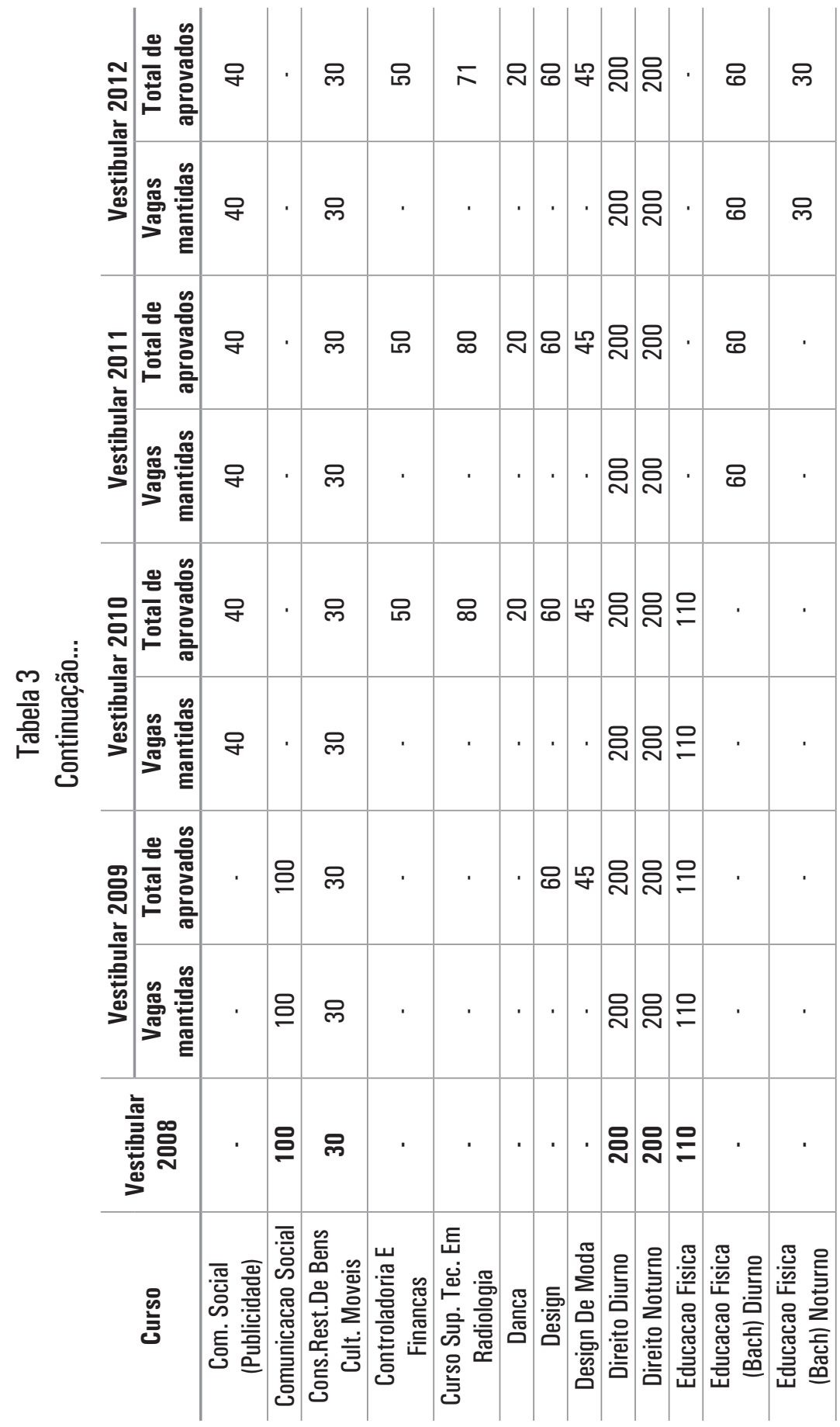




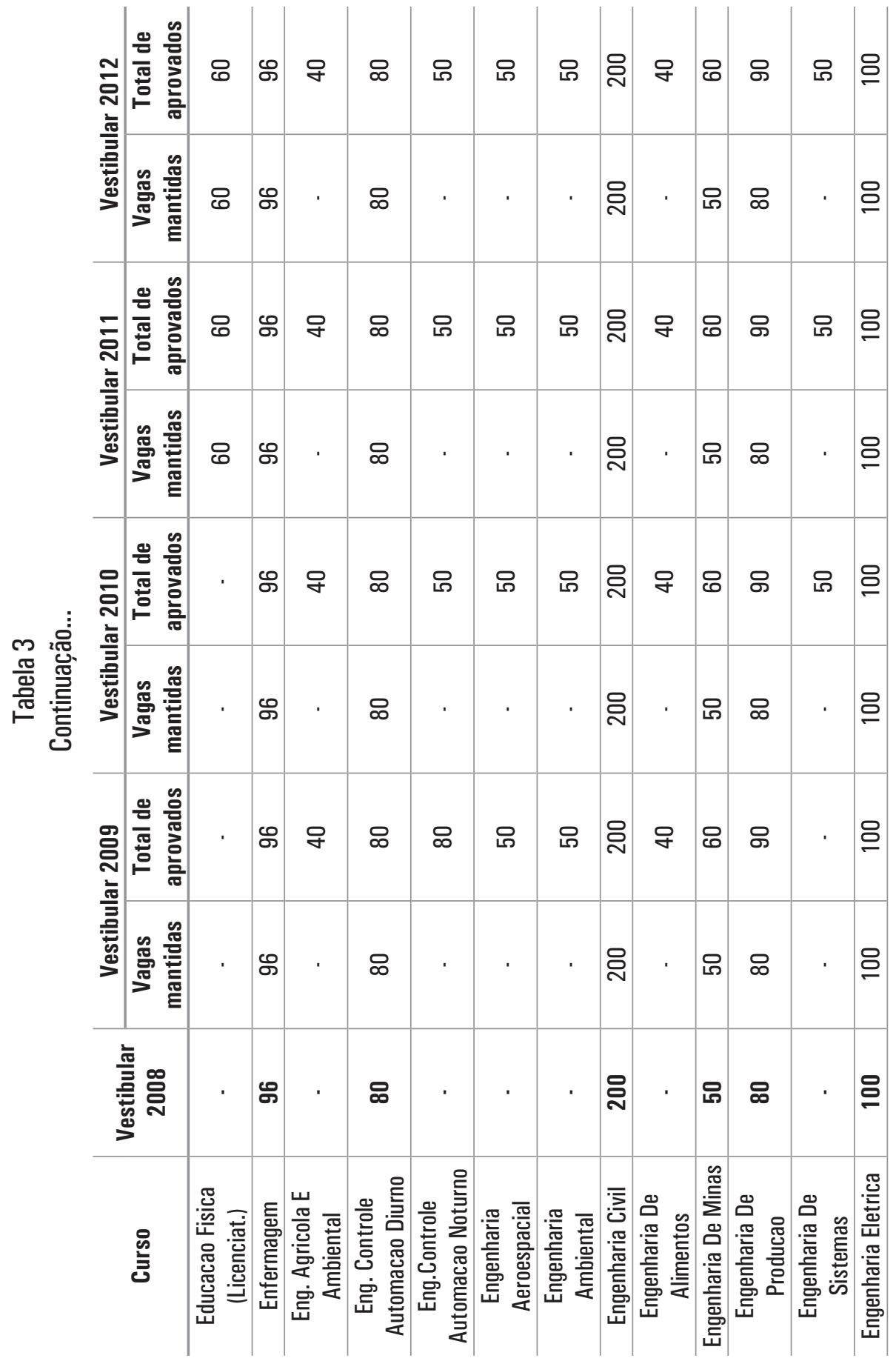




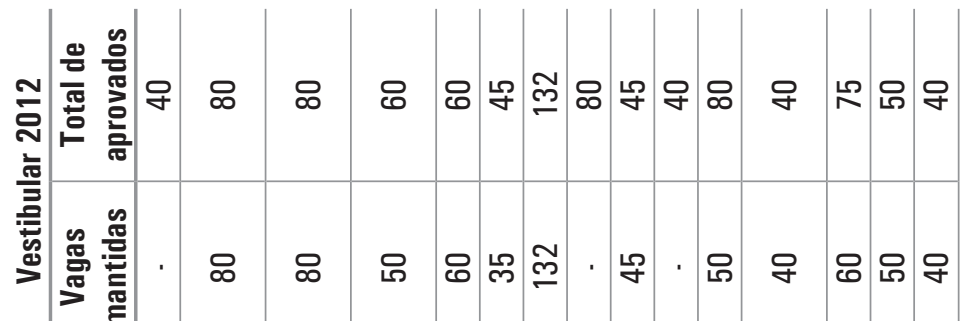

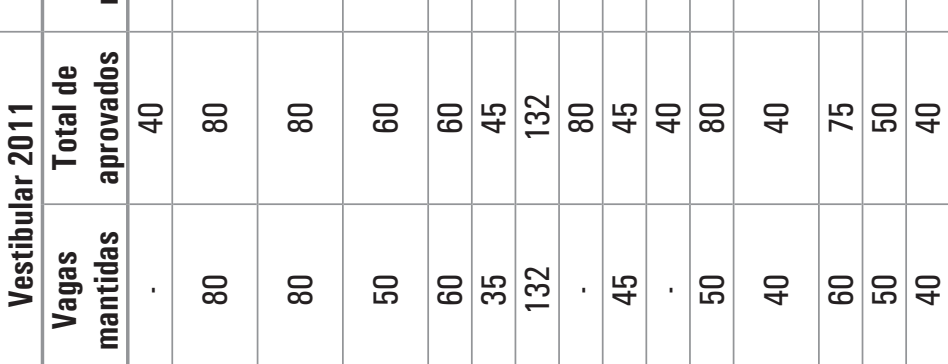

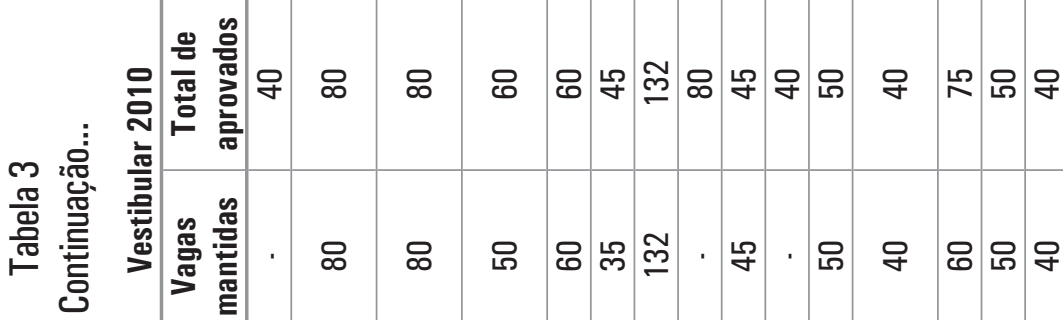
总

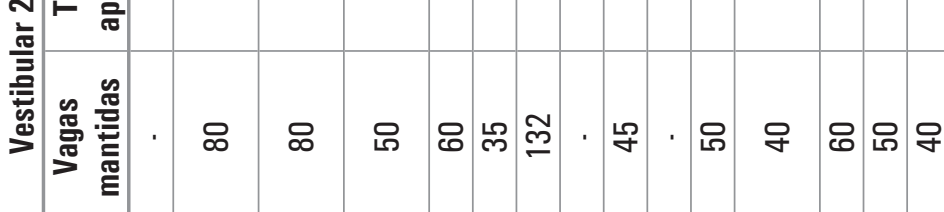

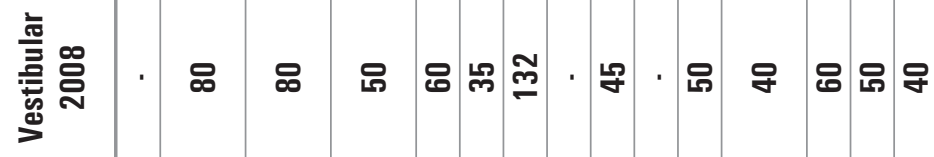

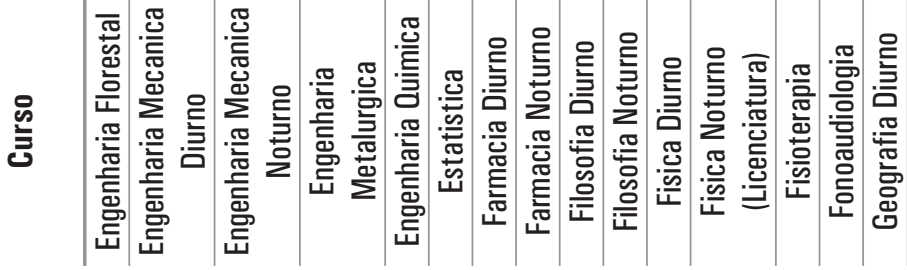




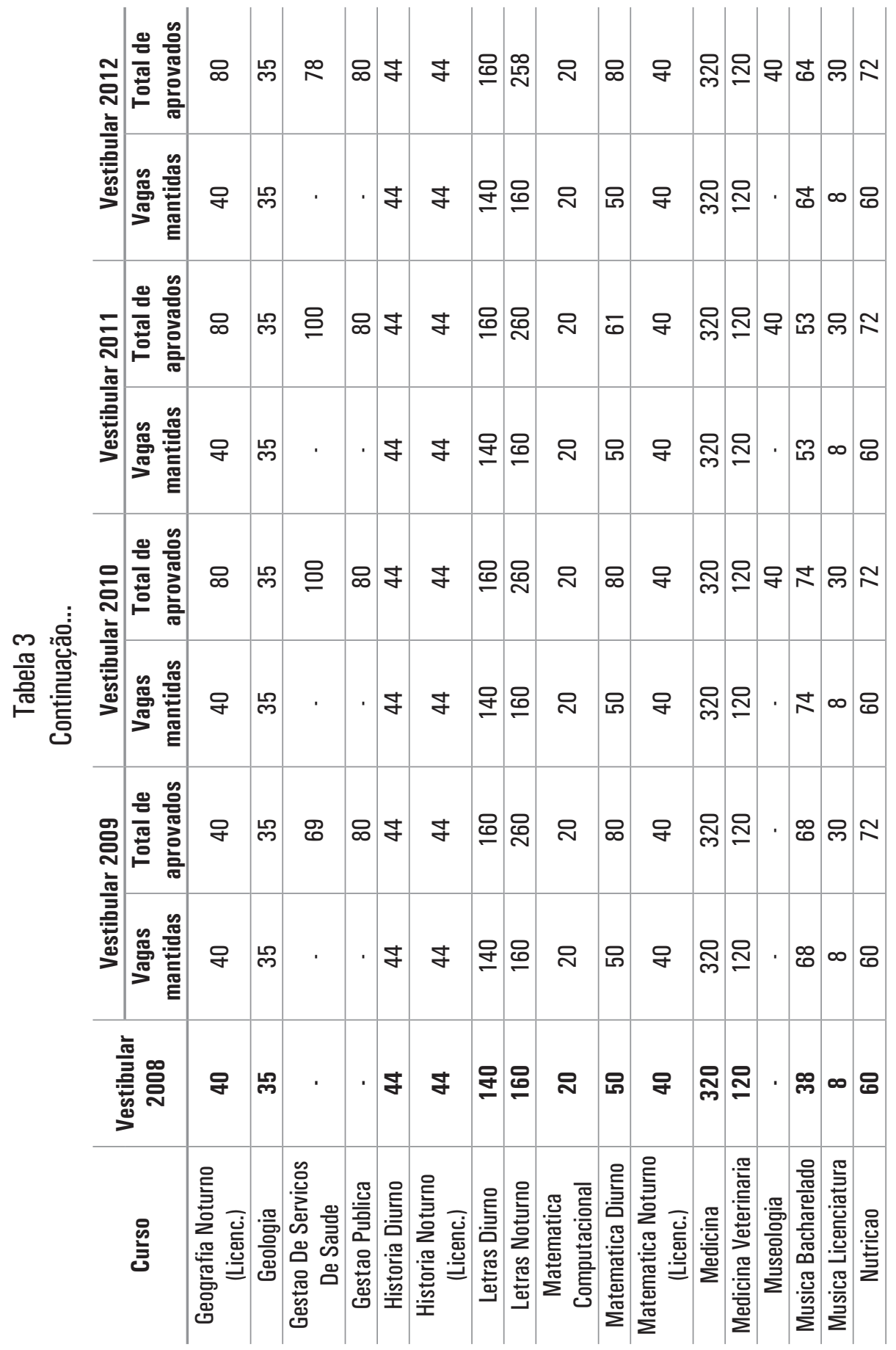




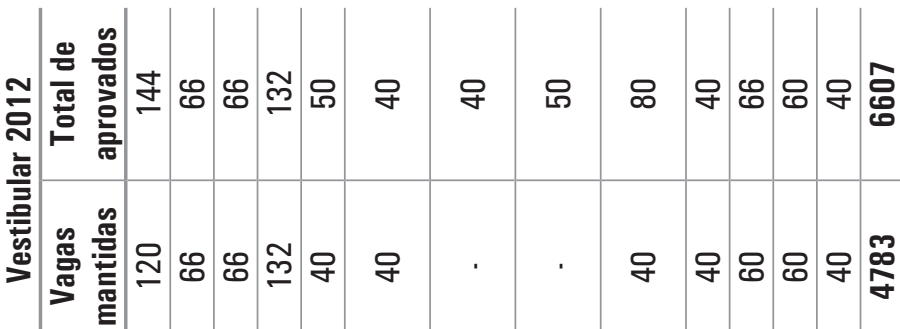

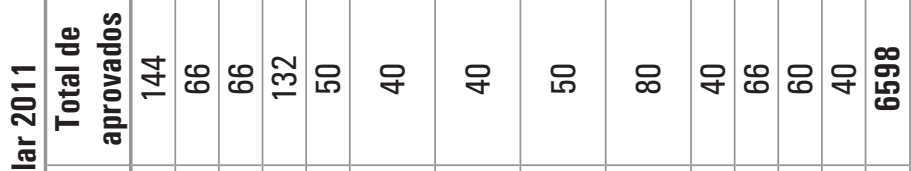

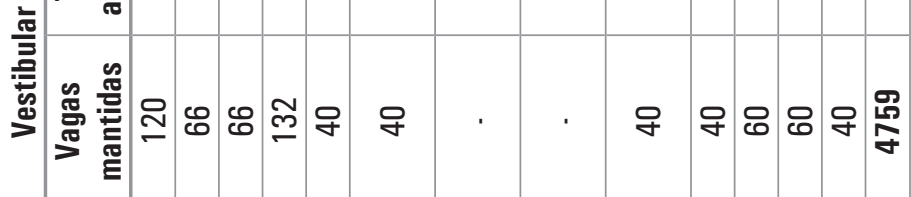

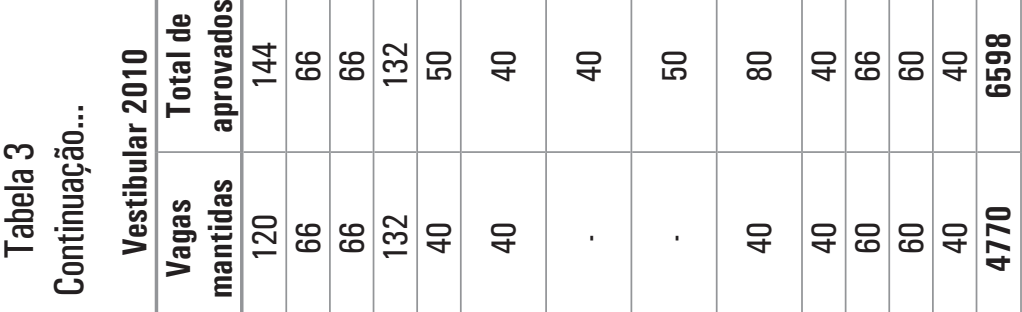

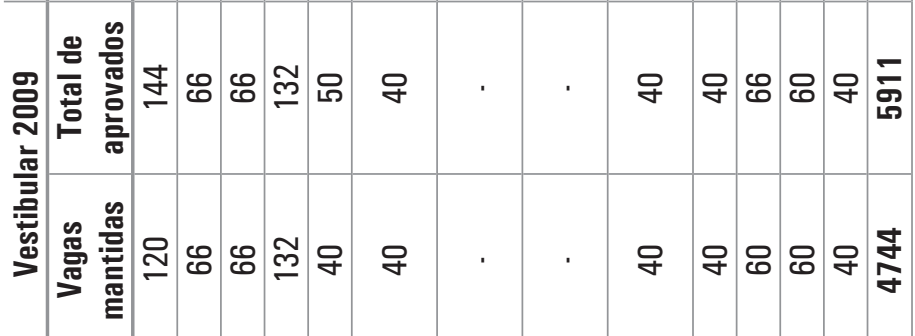

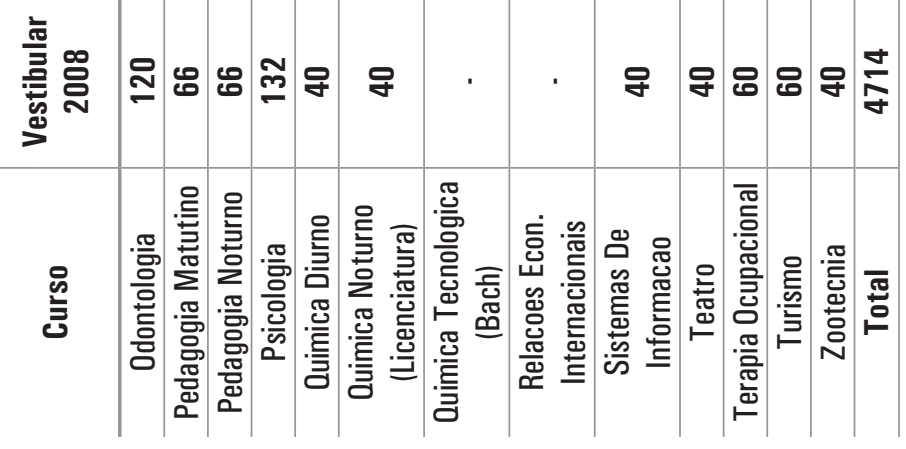

